\title{
Criminal justice continuum for opioid users at risk of overdose
}

\author{
Lauren Brinkley-Rubinstein ${ }^{\mathrm{a}, \mathrm{b}, *}$, Nickolas Zaller ${ }^{\mathrm{c}}$, Sarah Martino ${ }^{\mathrm{d}}$, David H. Cloud ${ }^{\mathrm{e}, \mathrm{f}}$, \\ Erin McCauley ${ }^{\mathrm{g}}$, Andrew Heise ${ }^{\mathrm{b}}$, David Seal ${ }^{\mathrm{h}}$
}

a Department of Social Medicine, University of North Carolina, Chapel Hill, United States

${ }^{\mathrm{b}}$ Center for Health Equity Research, University of North Carolina, Chapel Hill, United States

c University of Arkansas Medical Sciences, United States

${ }^{\mathrm{d}}$ Center for Prisoner Health and Human Rights, Miriam Hospital, Providence, RI, United States

e Emory University, United States

${ }^{\mathrm{f}}$ Vera Institute of Justice, United States

${ }^{\mathrm{g}}$ Cornell University, Ithaca, NY, United States

${ }^{\mathrm{h}}$ Tulane University School of Public Health and Tropical Medicine, United States

\section{H I G H L I G H T S}

- Individuals with criminal justice involvement are at increased risk of overdose post-release

- The Criminal Justice Continuum provides strategies to lower overdose risk among opioid users in the community

- These strategies include risk assessment, treatment and diversion, and overdose prevention

\section{A R T I C L E I N F O}

Keywords:

Criminal justice

Opioid overdose

\begin{abstract}
A B S T R A C T
The United States (US) is in the midst of an epidemic of opioid use; however, overdose mortality disproportionately affects certain subgroups. For example, more than half of state prisoners and approximately twothirds of county jail detainees report issues with substance use. Overdose is one of the leading causes of mortality among individuals released from correctional settings. Even though the criminal justice (CJ) system interacts with a disproportionately high number of individuals at risk of opioid use and overdose, few CJ agencies screen for opioid use disorder (OUD). Even less provide access to medication assisted treatment (e.g. methadone, buprenorphine, and depot naltrexone), which is one of the most effective tools to combat addiction and lower overdose risk. However, there is an opportunity to implement programs across the CJ continuum in collaboration with law enforcement, courts, correctional facilities, community service providers, and probation and parole. In the current paper, we introduce the concept of a "CJ Continuum of Care for Opioid Users at Risk of Overdose", grounded by the Sequential Intercept Model. We present each step on the CJ Continuum and include a general overview and highlight opportunities for: 1) screening for OUD and overdose risk, 2) treatment and/or diversion, and 3) overdose prevention and naloxone provision.
\end{abstract}

\section{Introduction}

The United States (US) is in the midst of an epidemic of opioid use; associated overdose deaths have risen at an alarming rate in recent years. From 2000 to 2014, the rate of opioid-involved overdose deaths increased by $200 \%$ (Rudd et al., 2016). Opioids and opiates-such as prescription painkillers, heroin, and fentanyl-were responsible for over 52,404 deaths nationwide in 2015. The number of American lives lost to opioid overdose each year is comparable to those lost at the peak of the AIDS epidemic or by the end of the Vietnam War. Over the past two decades, non-medical prescription opioid use contributed substantially to rising overdose rates (Calcaterra, Glanz, \& Binswanger, 2013; Cerdá et al., 2013; Kenan, Mack, \& Paulozzi, 2012). In more recent years, national initiatives to reduce opioid prescribing have produced modest declines in the number of prescription opioids dispensed (Dart et al., 2015). However, from 2010 to 2014, the rate of heroin-involved overdose deaths in the US increased three-fold (Compton, Jones, \& Baldwin, 2016). As persons with opioid use disorder shift from non-medical prescription opioid use to heroin, the epidemic of opioid overdose has been exacerbated by contaminated

\footnotetext{
* Corresponding author at: Department of Social Medicine, University of North Carolina, Chapel Hill, 333 S. Columbia Street, Chapel Hill, NC 27516, United States.

E-mail address: Lauren_Brinkley@med.unc.edu (L. Brinkley-Rubinstein).
} 
heroin supplies. Since 2013, illicitly-manufactured fentanyl analogs have been combined with or substituted for heroin (Centers for Disease Control and Prevention \& CDC Health Advisory, 2015). Several states have documented increases in fentanyl-related overdose fatalities. From 2013 to 2014, drugs seized by law enforcement that contained fentanyl increased by $426 \%$, and, during that same time period, fentanyl-involved overdose deaths increased by $80 \%$ (Gladden, Martinez, \& Seth, 2016).

Opioid use disorder (OUD) and overdose disproportionately affect certain subgroups. Approximately $24-36 \%$ of all people who are addicted to heroin pass through US prisons and jails each year (Boutwell et al., 2006). Recent research has demonstrated that $63 \%$ of individuals who are incarcerated in local jails report issues with substance use and $58 \%$ of individuals in state-run criminal justice (CJ) facilities have substance dependence (Bronson et al., 2017). Following release from incarceration, people experience greatly elevated risk of fatal opioid overdose as compared to the general population and to other times when they are using (Binswanger et al., 2007, 2011, 2013; Farrell \& Marsden, 2008; Merrall et al., 2010). A study in Washington State found that overdose was the leading cause of death among those who were previously incarcerated (Binswanger et al., 2013).

While the CJ system interacts with a disproportionately high number of individuals at risk of opioid use and overdose, the current paradigm of punishment rather than treatment does not facilitate the use of effective and coordinated interventions. Few CJ institutions screen for OUD using a validated measure and even less provide access to medication assisted treatment (e.g. methadone, buprenorphine, and depot naltrexone) (MAT), which is one of the most effective tools to combat addiction and lower overdose risk (Miller, Griffin, \& Gardner, 2016; Green et al., 2018). However, there is an opportunity to implement programs at several points across the $\mathrm{CJ}$ system including during: 1) law enforcement interactions; 2) court hearings (pre-and-post disposition); 3) pre-trial detention, jail, and prison; 4) community re-entry from jails and prisons; and 5) probation and parole. In the current paper, we introduce the concept of a "CJ Continuum of Care for Opioid Users at Risk of Overdose" that elucidates opportunities for screening and assessment, treatment and/or diversion, and overdose prevention among those involved in the CJ system. This continuum of care is based on the Sequential Intercept Model developed by Munetz and Griffin (Munetz \& Griffin, 2006).

\section{The CJ continuum of Care for opioid users at risk of overdose}

As originally conceptualized, the Sequential Intercept Model (SIM) provides a theoretical framework for communities to reduce incarceration rates among the mentally ill. The Model flows through a series of five intercepts; each aims to divert individuals from the traditional CJ system and into treatment. Necessarily, the SIM, as originally designed, does not focus on incarceration as a point of intervention-the CJ Continuum of Care for Opioid Users at Risk of Overdose presented in this paper diverges in this way. In the current paper, we have adapted the SIM to include five continuum points (see Fig. 1). Below we present each step on the CJ Continuum and include a general overview and highlight opportunities for: 1) screening for OUD and overdose risk, 2) treatment and/or diversion, and 3) overdose prevention and naloxone provision. Enveloped in each of these categories are the identification of those with OUD and/or at risk of overdose; opportunities for medication assisted treatment; and, finally, strategies for naloxone provision.

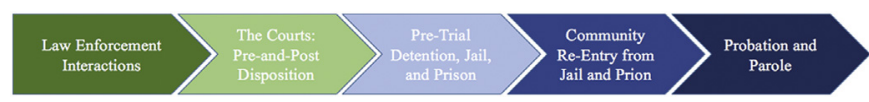

Fig. 1. The CJ Continuum for Opioid Users at Risk of Overdose.

\subsection{Law enforcement interactions}

State and local police officers work at the gateway of the CJ system. As first responders, law enforcement officers (LEO) may encounter opioid users who are actively overdosing, using, or in withdrawal and/ or who are buying, selling, or in possession of opioids. While LEO are not trained to make clinical assessments or recommendations regarding an individual's opioid use, they can play an integral role in overdose reversal and make recommendations for consideration of treatment. In addition, sheriffs are often elected officials who set the tone for how their jurisdiction responds to problems rooted in substance use. They can be powerful messengers in advocating for the expansion of health promotion and harm reduction interventions that are accessible via the health and social service systems and not contingent on arrest, prosecution, or sentencing.

\subsubsection{Screening for OUD and overdose risk and diversion}

Law Enforcement Assisted Diversion (LEAD) is a pre-booking diversion program specifically designed for substance users in the US. The program was initially established in 2011 in Seattle, Washington, and offers diversion from arrest into case management based on the offense type (low level drug and prostitution). LEAD often includes collaborations with community partners to conduct assessments and referral to substance use treatment, though treatment is not a mandated requirement of participation. Importantly, after being stopped by a LEO, the LEO can screen for LEAD eligibility. If eligible, individuals are referred to a LEAD case manager for intake into the program. A recent longitudinal analysis of program data among 318 participants (203 allocated to the LEAD program and 115 allocated to a control condition) revealed that LEAD participants had $60 \%$ lower odds of arrest at six months post-program entry and $58 \%$ and $39 \%$ lower odds of arrest and being charged with a felony, respectively, at three years post-program entry (Collins, Lonczak, \& Clifasefi, 2017). This preliminary success of the LEAD program has resulted in additional municipalities across the US developing LEAD sites in Baltimore, Maryland; Fayetteville, North Carolina; Santa Fe, New Mexico; Albany, New York; Portland, Oregon; and Huntington, West Virginia; with even more cities currently in various stages of program planning and development.

\subsubsection{Overdose prevention and education}

One of the most significant ways in which LEO have shifted their focus toward a public health approach to opioid addiction is through prevention of overdose death. During the past several years, police departments throughout the US have engaged in overdose education and training and have begun to carry naloxone to reverse opioid overdose. LEO in more than 200 law enforcement agencies across the country now carry naloxone (Davis, Carr, Southwell, \& Beletsky, 2015). Data collected across multiple sites suggest that overdose training and use of naloxone is viewed favorably by officers and increases knowledge about overdose and confidence in ability to reverse an overdose event (Green, Zaller, Palacios, et al., 2013; Ray \& K, 2015; Wagner, Bovet, Haynes, et al., 2016). Furthermore, in areas where LEO have received training in overdose prevention and naloxone administration, there has been a marked decrease in overdose related mortality (US law enforcement who carry Naloxone, 2017). A recent analysis of data from Lorain County, Ohio, over a three-year period documented that a naloxone training program among more than 500 police officers from the county sheriff's office and city jurisdictions resulted in a nearly $80 \%$ survival rate among individuals to whom LEO administered naloxone during an overdose event (Rando, Broering, Olson, et al., 2015). In Quincy, Massachusetts, one of the first jurisdictions to approve LEO to carry naloxone, LEO have reversed more than 200 overdoses since 2010 (Leger, 2014). In North Carolina, the North Carolina Harm Reduction Coalition (NCHRC) reports that LEO have reversed 403 overdoses as of February of 2017 in the state (US law enforcement who carry Naloxone, 2017). 


\subsection{The courts}

Criminal courts are underutilized settings for establishing opioid treatment and overdose prevention initiatives. Public defenders, judges, and managers of court-based diversion programs have an especially important role to play. The feasibility of screening defendants for OUD and delivering overdose education and naloxone distribution programs in court systems depends on the nature of the criminal proceeding and its timing in the adjudication process.

\subsubsection{Screening for OUD and overdose risk}

As a general principle, courts should focus on screening and linking people with OUD to treatment in the community as early as possible. For example, an arraignment is usually a defendant's first court appearance that occurs within a few hours or days after an arrest, making it an important stage for identifying people with OUD. At arraignment, judges make crucial decisions that either result in a defendant being released to the community (e.g. dismissal, conditional discharge, or bail posted), or being sent to jail (e.g. cannot afford to pay bail, held pending a trial, or sentenced to jail following guilty plea). However, the fast-paced nature of arraignments and the limited time defense attorneys have to meet with their clients makes it extremely difficult for lawyers to reliably assess whether their client has OUD and advocate for outcomes that mitigate overdose risk. To address this, courts can work with police and jails to modify booking procedures that occur between arrest and arraignment to screen people for overdose risk and, with consent, relay that information to their defense attorneys. For example, when a LEO books a person into jail following an arrest, a nurse or other staff member usually conduct an medical screening with each person to identify any urgent health needs warranting immediate medical attention (Paris, 2009). Screening for OUD could easily be incorporated into this screening.

Once reliable information is collected, legal protocols are needed that allow healthcare providers to relay information about a patient's overdose risk, with consent, to their defense attorneys before arraignment. Streamlining information about person's substance use treatment needs, recent service engagement, and overdose risk before arraignment helps defense lawyers advocate to keep their clients out of jail and connect them to treatment in the community as early as possible in the adjudication process. In conjunction, to maximize the impact of these information sharing strategies, public health professionals should conduct educational trainings for judges and prosecutors that convey the implications of pre-trial detention for overdose risk among people with opioid dependencies.

\subsubsection{Treatment and/or diversion}

Most diversion programs are court-based, and operate at later stages of adjudication (i.e. post-arraignment). These include drug courts and other specialized courts that provide people charged with a crime the option to participate in mandated treatment as part of a conditional plea bargain or sentence alternative to going to jail or prison.

Drug courts have become a fixture in the landscape of CJ systems over the past two decades. Today, there are approximately 3,000 drug courts in the US (Drug Courts, 2017). Drug courts vary in their willingness and organizational capacity to deliver evidence-based treatments for OUD and overdose prevention (Matusow et al., 2013). Results from a recent survey of drug courts across the US demonstrated that almost all drug courts had opioid addicted participants, but only $47 \%$ offered buprenorphine or methadone and only $56 \%$ offered naltrexone (Drug Courts, 2017). Despite the scientific evidence supporting the use of MAT, many drug courts continue to enforce strict rules rooted in abstinence and zero-tolerance philosophies, which often exclude people who use MAT from enrolling. Some courts also impose sanctions or terminate enrollment for those who initiate MAT as part of their recovery process (Csete \& Catania, 2013; Matusow et al., 2013). These practices, often determined by the attitudes and opinions of judges and court personnel, do not reflect Federal funding requirements for drug courts or recommendations from the National Association for Drug Court Professionals and other leading authorities (National Association of Drug Court Professionals, 2010; U.S.D.O. Justice, 2016). Drug courts should offer MAT as a treatment option to participants and individuals prescribed MAT should not be excluded from participation. This may require training for court personnel and local treatment providers, as well as legislative and regulatory changes. For example, states should enact laws that mandate drug courts to offer MAT as a condition for receiving funding, or establish regulatory agencies to conduct oversight of drug courts and issue fines to jurisdictions that fail to adhere to bestpractices in addiction medicine. In 2015, New York State passed legislation that forbids drug courts from forcing people off of MAT as a condition of participation (State of New York 2015-2016, 2015).

\subsubsection{Overdose education and prevention}

At each stage in this process, court-based stakeholders can play a role in incorporating overdose education and naloxone distribution into their activities. At the arraignment stage, many public defense agencies have social workers on staff who can implement overdose education and naloxone distribution programs in courtrooms, regardless of a person's legal disposition. It is critical for staff of any court-based diversion program to immediately assess a potential client's risk for overdose, and provide access to overdose education and naloxone for those reporting or displaying risk factors.

\subsection{Incarceration}

People are incarcerated and in jails and prisons. Jails are locally operated short-term facilities for individuals awaiting trial, sentencing, or serving short sentences (typically for less than a year). Prisons are run by the state or federal government, and hold individuals serving longer sentences. As recently incarcerated individuals are at an increased risk of overdose after release, the period of incarceration that proceeds community reentry is a pivotal intervention point for implementing overdose prevention programs, conducting risk assessments, and providing MAT.

\subsubsection{Screening for OUD and overdose risk}

Screening and assessment tools have been developed and are utilized to assess for OUD. A necessary and crucial step in addressing OUD and overdose among those who are incarcerated is to ascertain the magnitude of the problem. While we have provided examples of opportunities to screen individuals for OUD and overdose risk across the CJ continuum, we recognize that institutional level barriers may impede implementation. For example, many county jails, especially in rural areas, may lack appropriately trained personnel to screen/assess for OUD and may also lack confidential space in which to conduct screenings/assessments. However, jail staff can administer rapid opioid screening tools, such as the RODS, in only a few minutes and can partner with community based substance use providers in order to provide more in-depth clinical assessments, as appropriate. (Wickersham, Azar, Cannon, Altice, \& Springer 2015).

\subsubsection{Treatment and/or diversion}

Individuals who are incarcerated who are flagged for OUD should be given a clinical assessment to determine options for MAT in addition to relevant on-site counseling and recovery supports. Numerous studies have documented far-reaching benefits to implementing MAT in correctional populations (Sharma et al., 2016); including post-incarceration reductions in illicit opioid use (Kinlock et al., 2009; Mattick et al., 2009), criminal behavior (Deck et al., 2009), mortality and overdose risk (Degenhardt et al., 2011; Kerr et al., 2007; Green et al., 2018), and HIV risk behaviors (MacArthur et al., 2012). The World Health Organization (World Health Organization Dept. of Mental Health Substance Abuse, W.H.O. and U.N.O.o.D.a.C, 2009) and the National Institute on 
Drug Abuse (Abuse, N.I.o.D, 2014) strongly endorse the use of MAT to treat opioid use disorder in incarcerated populations; nonetheless, there has been little to no implementation or routinization of MAT in US jail and prison settings.

In the US, there are over 3200 local and county jails and 1800 state and federal prisons, but few correctional facilities offer addiction treatment using MAT with methadone, buprenorphine or naltrexone (Lee et al., 2015; Vestal, 2016). Among correctional facilities that do offer MAT, the majority restrict treatment to persons who are pregnant (Nunn et al., 2009) or to those who were engaged in methadone treatment prior to incarceration, and it is usually only provided on an accelerated 30-day taper protocol (Rich et al., 2015). In the context of the current opioid epidemic, there has been some movement toward adoption of MAT programs. The Rhode Island Department of Corrections recently implemented the first of its kind comprehensive MAT program that allows individuals to initiate or continue, where clinically appropriate, on methadone, buprenorphine, or depot naltrexone.

Earlier this year the National Governor's Association (NGA) launched a "learning lab" where correctional entities that are interested in MAT program implementation can learn from more established jurisdictions. The initiative included North Carolina, Alaska, Indiana, Kansas, Minnesota, New Jersey, Virginia, and Washington. Participation in the NGA project includes developing and executing short-term action plans to address overdose risk and opioid addiction in prisons. Continued adoption of MAT programs in correctional settings will require dissemination of implementation best practices, mentorship from jurisdictions who have long had MAT programs in place, and research related to contextual and institutional factors that may impede (e.g. correctional attitudes toward MAT) or facilitate (buy-in from key policy makers) success of MAT in closed settings.

\subsubsection{Overdose education and prevention}

Overdose prevention education programs should be provided in jails and prisons, with special attention paid to the limitations that various types of correctional facilities may have in place. These overdose prevention programs should provide information for people who are incarcerated related to: how to identify signs of a possible overdose, the risk factors for overdose, the policies and laws in place that are relevant (e.g. Good Samaritan Laws), where to get services (e.g. syringe exchange) in the community and the medical risks associated with injection drug use (e.g. hepatitis C, HIV). In addition, naloxone should be available in correctional facilities to medical and correctional staff members to use in an emergency. A new innovation called a "NaloxBox", similar to defibrillator boxes, that are often available in public spaces, could be used in correctional facilities (NaloxBox, n.d.). Several NaloxBoxes could be placed strategically in various areas (e.g. medical clinic, intake), so officers and staff can have quick access to naloxone in the event of an overdose.

\subsection{Community re-entry}

Studies have shown that people with OUD not only experience adverse consequences during incarceration, but also have poorer drugrelated outcomes post-release during community re-entry (Prendergast, 2009). The immediate post-release period is a time of extreme overdose risk due to loss of opioid tolerance during incarceration, thereby increasing risk of fatal and non-fatal overdose. Providing people with OUD access to treatment and prevention services during community reentry is essential.

\subsubsection{Screening for OUD and overdose}

To our knowledge, no overdose risk indexes exist to evaluate an individual's risk of opioid overdose post-release. An overdose risk index should be developed that considers community-based risks and individual and institutional features, including lack of social support, financial deprivation, exposure/access to drugs, homelessness, history of overdose, and intention to return to opioid use (Brinkley-Rubinstein et al., 2017). This simple, evidence-based screening for risky opioid use and overdose should be added to all jail/prison discharge processes and could be shared with community-based treatment facilities. In addition, community-based MAT and other substance use treatment providers should screen for recent incarceration as a part of program intake and target these individuals for intensive support services.

\subsubsection{Treatment and/or diversion}

Among people who have successfully initiated or continued MAT post-release, consideration needs to be given to ensure that effective connections are being made to community treatment providers. Research has shown that few people follow up on MAT referrals postrelease (Kinlock et al., 2008). In a set of interviews with people who had a history of current or past opioid use, Fox et al. found that factors influencing relapse included (1) exposure to drug use in halfway houses or shelters, (2) loneliness and isolation, and (3) strained family or interpersonal relationships (Fox et al., 2015). Participants also reported resistance to MAT and the associated stigmas of treatment; they expressed a desire to use willpower to avoid dependency and relapse. In addition, a recent research study among 396 individuals seeking treatment for OUD indicated that arrest increased the likelihood of relapse post-treatment (Kopak, Lawson, \& Hoffmann, 2018). Accordingly, community re-entry interventions should address contextual exposure to opioid use, psychosocial and interpersonal factors, re-arrest and re-incarceration, and individual-and-provider-level stigma and attitudes toward MAT. Programs that combine MAT with case-management services may enhance a client's likelihood of avoiding relapse. Beyond treatment support, case management services may include education, housing assistance, employment services, and social support (Beletsky, 2015; Seal et al., 2007; Wolitski \& t.P.S.S. Group, 2006).

\subsubsection{Overdose education and prevention}

Data suggest that few correctional facilities distribute naloxone to people re-entering the community (Green et al., 2015). Studies in Scotland and England (Parmar et al., 2017; Strang, Bird, \& Parmar, 2013) have found that the provision of naloxone training and supplies to people leaving prison significantly reduces post-release overdose fatality rates. For individuals who return to and/or initiative injection drug use, it is essential that they have access to clean needles through needle exchange programs, medical clinics, and/or pharmacies (CDC, 2016). Though still limited in the US, a growing number of correctional systems in the US are implementing naloxone training and distribution to people leaving correctional facilities. Facilities with significant numbers of opioid users should consider implementation of similar programs to combat post-release overdose. Community-based providers who screen for incarceration can also provide overdose education at the point of program entry and provide naloxone.

\subsection{Parole and probation}

In the US, over 4.5 million people are under the supervision of probation or parole, often referred to as community corrections. Probation generally refers to a period during which an individual must comply with a defined set of conditions in lieu of being detained in a correctional facility. In some states that use split prison/probation sentencing, people may continue to be under probation supervision after serving a jail/prison sentence. While functionally similar to probation, parole is a system created to supervise people being released from prison prior to the completion of their sentence. Violations of probation and parole conditions may result in incarceration or re-incarceration. Probation and parole officers are responsible for holding their clients accountable to these conditions, while also supporting rehabilitation and client success in the community. Given their frequency of contact with many justice-involved individuals and their unique role in the system, probation and parole officers have an integral role to the 
play in identifying individuals with OUD, supporting treatment, and preventing overdose.

\subsubsection{Screening for OUD and overdose}

While some probation and parole officers may have access to information about clients' opioid use histories, many may need to do an initial OUD screening. Probation officers should be trained to use evidence-based screening tools that screen for opioid use disorder, and have a screening protocol. All community corrections staff will need knowledge of available community treatment resources, and may formally partner with community-based treatment providers to assist with further assessment and to develop treatment plans.

\subsubsection{Treatment and/or diversion}

Supporting clients with OUD may require taking an approach to recovery that does not conform to a jurisdiction's existing community corrections framework. SAMHSA guidance reflects the need for a nuanced approach to relapse within a community corrections context, stating that CJ agency staff must work collaboratively with providers to develop a "range of responses" to relapse, and appropriate graduated sanctions. SAMHSA best practices stress the importance of treating relapse as part of the recovery process, as opposed to a personal failure, and an opportunity to strengthen the recovery support being provided by CJ agency staff (Substance Abuse and Mental Health Services Administration, 2005).

When it comes to treatment, it is essential that probation and parole officers support the treatment plan developed by a client's treatment provider. This includes supporting use of all types of MAT for OUD, as prescribed by a medical provider. While negative personal beliefs about MAT among community corrections officers present considerable barriers to encouraging the use of this evidence-based treatment for people on probation and parole, establishing strong communication and partnerships with community treatment providers can change staff perceptions and increase intent to refer to treatment (Friedmann et al., 2012; Friedmann et al., 2015).

\subsubsection{Overdose education and prevention}

Probation and parole staff should receive training in how and when to administer naloxone, and have on-site naloxone access (American Society of Addiction Medicine, 2016). In 2015, the Pennsylvania Board of Probation and Parole trained field supervision staff in recognizing the signs of an overdose as well as naloxone administration and provided each Board office with a naloxone kit (Pennsylvania Board of Probation and Parole, 2015). A true harm reduction approach would use probation and parole as a site for naloxone distribution, and community corrections agencies should consider their offices' potential to participate more aggressively in overdose prevention. States can also encourage overdose prevention by extending Good Samaritan law$\mathrm{s}$-which protect individuals who may be using or holding drugs or drug paraphernalia from prosecution when they report an overdose-to include individuals on probation and parole.

\section{Discussion}

Given the high prevalence of OUD among CJ involved populations and their extreme risk for opioid-related overdose, there is a critical need to bolster efforts to identify, treat, and prevent overdose. The SIM is a useful framework that we have used to illuminate each point along the CJ continuum (i.e. law enforcement, court, incarceration, re-entry, probation and parole). Each intercept presents an opportunity to improve outcomes for opioid users by identifying those at risk, promoting treatment, preventing overdose, and potentially assuaging the collateral consequences of CJ involvement. However, in order to fully take advantage of opportunities to intervene, there are numerous logistical, policy and resource related challenges that must be considered. Correctional, community, and individual attitudes related to MAT must be researched and effective training and strategies developed to overcome MAT stigma, such as educating CJ staff about the relevant health and CJ-related (e.g. lower rates of re-incarceration) benefits (Miller, Miller, \& Barnes, 2016). In addition, at the local level, political will may restrict widespread implementation of OUD and overdose programs for CJ populations. Therefore, guidance that aids in how to gradually adopt OUD-related programs in challenging CJ environments should be developed. Just as programs at each step of the continuum require adjustment to fit each individual environment (e.g. a screening tool that is best suited for jails may not be appropriate for probation and parole settings), consideration of community and regional contexts is imperative. For instance, a state like Rhode Island wherein the Department of Corrections has jurisdiction over all incarcerated persons in jail and prison cannot be compared to a state like North Carolina that has a state prison system and 100 separate county jails. In the same way, what is possible in a rural, under-resourced county, will not always be comparable to what can be implemented in some big, urban environments.

In order to ensure access to MAT and other support services, appropriate resources and funding need to be allocated to all CJ-related agencies and community based treatment providers who serve CJ involved individuals. With the current attention to the national opioid epidemic, there is a tremendous opportunity to direct resources where they are most needed to successfully stem the tide of opioid addiction and overdose. With the passage of the 21st Century Cures Act in 2017, Congress demonstrated a commitment to funding MAT for OUD. However, more resources need to be directed specifically to institutions and agencies within the $\mathrm{CJ}$ system, as these entities interact with a high proportion of individuals with OUD and can have a tremendous impact on treating OUD and preventing opioid overdose mortality. In addition, dedicated funding needs to be directed toward rigorous evaluation of any new MAT initiatives in correctional settings in order to determine best practices and a blueprint for future use. However, we acknowledge that in CJ settings there may be realistic challenges to opioid-relevant program implementation. For instance, funding allocations can be unpredictable and change from year to year. In addition, CJ systems' healthcare costs are already high as people who are incarcerated have a disproportionately high burden of disease. For law enforcement agencies, the cost of naloxone may be prohibitive leading to an inability to keep an adequate supply on hand at all times. Finally, it must be noted that practical concerns related to contagion health problems must also be considered. Law enforcement officers or other CJ entities could come into contact with very powerful residual fentanyl powder when responding to an overdose underscoring the need to address public health and officer safety needs in any comprehensive CJ relevant program to combot opioid use or overdose risk.

Despite these issues, the public health community should continue to advocate for additional resources to treat opioid addiction and its related consequences in the $\mathrm{CJ}$ system. In particular, more can be done to reduce the costs associated with naloxone, such as rate negotiations between states. The recently released report from the President's Commission on Combatting Drug Addiction and the Opioid Crisis, explicitly calls for increased federal resources to expand access to both MAT and naloxone, including within the CJ system. The public health community has an obligation to continue to advocate for federal, state, and local resources be directed toward evidence-based addiction prevention, treatment, and recovery services within the CJ system and across the country as a whole.

One important, final consideration is that focusing on the CJ system as a site of intervention may have the unintended consequences of extending the reach of the system itself. For example, programs that rely on intense supervision and are tied to CJ outcomes (e.g., probation conditions or court mandates) have the potential to lead to harsher punishment for someone battling addiction and prone to relapse. The SIM, the framework which informs this paper, was initially conceptualized to identify opportunities to provide clinically appropriate 
interventions to individuals with behavioral health disorders to prevent them from entering into the CJ system or from becoming more deeply involved in the system (Miller, Griffin, \& Gardner, 2016). Therefore, it is imperative that those working within the CJ continuum are aware of this dynamic and encourage training and education for $\mathrm{CJ}$ practitioners to prevent the creation of overly punitive programming.

\section{Conclusion}

CJ involved individuals are at increased risk of overdose; however, the CJ system's traditional orientation to punishment rather than public health has resulted in a dearth of treatment options. Herein, we have provided specific guidance, on each point of the CJ continuum, to optimize implementation of screening, treatment/diversion, and overdose education and naloxone provision programs. While we acknowledge the existence of barriers such as cost, attitudes toward MAT, and local and facility level capacity, CJ-based addiction and overdose initiatives are necessary to address the current opioid epidemic.

\section{Role of funding sources}

Funding for this study was provided by The Brown Initiative in HIV and AIDS Clinical Research for Minority Communities, R25MH083620, The UCLA HIV/AIDS, Substance Abuse and Trauma Training Program (HA-STTP), R25DA035692, The HIV and Other Infectious Consequences of Substance Abuse, T32DA013911, and The Lifespan/ Brown Criminal Justice Research Program on HIV and Substance Use, R25DA037190.

\section{Contributors}

LBR was the lead writer and conceptualized the article in combination with DS. NZ, DC, EM, SM, and AW contributed to writing in accordance with their criminal justice and/or opioid overdose expertise.

\section{Conflict of interest}

All authors declare that they have no conflicts of interest.

\section{References}

Abuse, N.I.o.D (2014). Principles of drug abuse treatment for criminal justice populations: A research based guide. Bethesda, MD: National Institutes of Health, National Institute on Drug Abuse (NIH publication No. 11-5316, revised).

American Society of Addiction Medicine (2016). Public policy statement on the use of Naloxone for the prevention of opiod overdose deaths.

Beletsky, L., et al. (2015). Fatal re-entry: Legal and programmatic opportunities to curb opiod overdose among individuals newly released from incarceration. School of law faculty publications17.

Binswanger, I. A., et al. (2007). Release from prison-A high risk of death for former inmates. New England Journal of Medicine, 356(2), 157-165.

Binswanger, I. A., et al. (2011). Risk factors for all-cause, overdose and early deaths after release from prison in Washington state. Drug and Alcohol Dependence, 117(1), 1-6.

Binswanger, I. A., et al. (2013). Mortality after prison release: Opiod overdose and other causes of death, risk factors and time trends from 1999 to 2009. Annals of Internal Medicine, 159(9), 592-600.

Boutwell, A. E., et al. (2006). Arrested on heroin: A national opportunity. Journal of Opioid Management, 3(6), 328-332.

Brinkley-Rubinstein, L., Carr, D., Davis, C., Zaller, N., Delany-Brumsey, A., Pope, L., .. Rich, J. (2017). Addressing excess risk of overdose among recently incarcerated people in the USA: harm reduction interventions in correctional settings. International Journal of Prison Health, 3(1), 25-31.

Bronson, J., et al. (2017). Drug use, dependence, and abuse among state prisoners and jail inmates, 2007-2009. Washington, DC: Bureau of Justice Statistics.

Calcaterra, S., Glanz, J., \& Binswanger, I. A. (2013). National trends in pharmaceutical opioid related overdose deaths compared to other substance related overdose deaths: 1999-2009. Drug and Alcohol Dependence, 131(3), 263-270.

CDC (2016). HIV and injection drug use: Syringe services programs for HIV prevention. Atlanta, GA: V.H. National Center for HIV/AIDS, Sexual Trasmitted Diseases and Tuberculosis Prevention, Center for Disease Control.

Centers for Disease Control and Prevention, \& CDC Health Advisory (2015). Increases in fentanyl drug confiscations and fentanyl-related overdose fatalities. HAN Health
Advisory26 (October).

Cerdá, M., et al. (2013). Prescription opioid mortality trends in New York City, 1990-2006: Examining the emergence of an epidemic. Drug and Alcohol Dependence, 132(1), 53-62

Collins, S., Lonczak, H., \& Clifasefi, S. (2017). Seattle's law enforcement assisted diversion (LEAD): Program effects on recidivism outcomes. Evaluation and Program Planning, 64, 49-56.

Compton, W. M., Jones, C. M., \& Baldwin, G. T. (2016). Relationship between nonmedical prescription-opioid use and heroin use. New England Journal of Medicine, 374(2), $154-163$.

Csete, J., \& Catania, H. (2013). Methadone treatment providers' views of drug court policy and practice: A case study of New York state. Harm Reduction Journal, 10(1), 35.

Dart, R. C., et al. (2015). Trends in opioid analgesic abuse and mortality in the United States. New England Journal of Medicine, 372(3), 241-248.

Davis, C. S., Carr, D., Southwell, J. K., \& Beletsky, L. (2015). Engaging law enforcement in overdose reversal initiatives: Authorization and liability for naloxone administration. American Journal of Public Health, 105, 1530-1537.

Deck, D., et al. (2009). Medicaid coverage, methadone maintenance, and felony arrests: Outcomes of opiate treatment in two states. Journal of Addictive Diseases, 28(2), 89-102.

Degenhardt, L., et al. (2011). Mortality among regular or dependent users of heroin and other opioids: A systematic review and meta-analysis of cohort studies. Addiction, 106(1), 32-51.

Drug Courts. 2017

Farrell, M., \& Marsden, J. (2008). Acute risk of drug-related death among newly released prisoners in England and Wales. Addiction, 103(2), 251-255.

Fox, A. D., et al. (2015). Release from incarceration, relapse to opioid use and the potential for buprenorphine maintenance treatment: A qualitative study of the perceptions of former inmates with opioid use disorder. Addiction Science and Clinical Practice, 10, 2.

Friedmann, P. D., et al. (2012). Medication-assisted treatment in criminal justice agencies affiliated with the criminal justice-drug abuse treatment studies (CJ-DATS): Availability, barriers, and intentions. Substance Abuse, 33(1), 9-18.

Friedmann, P. D., et al. (2015). Effect of an organizational linkage intervention on staff perceptions of medication-assisted treatment and referral intentions in community corrections. Journal of Substance Abuse Treatment, 50, 50-58.

Gladden, R. M., Martinez, P., \& Seth, P. (2016). Fentanyl law enforcement submissions and increases in synethic opiod-involved overdose deaths-27 states, 2013-2014. Morbidity and Mortality Weekly Report, 65(33), 837-843.

Green, T. C., Bowman, S. E., Ray, M., McKenzie, M., Lord, S. E., \& Rich, J. D. (2015). Development of an incarceration-specific overdose prevention video: "Staying Alive on the Outside". Health Education Journal, 74, 627-637.

Green, T. C., Zaller, N., Palacios, W. R., et al. (2013). Law enforcement attitudes toward overdose prevention and response. Drug and Alcohol Dependence, 133(2), 677-684.

Green, T. C., Clarke, J., Brinkley-Rubinstein, L., Marshall, B. D. L., Alexander-Scott, N., Boss, R., \& Rich J.D., J. D. (2018). Postincarceration fatal overdoses after implementing medications for addiction treatment in a statewide correctional system. JAMA Psychiatry. 14http://dx.doi.org/10.1001/jamapsychiatry.2017.4614 Published online February.

Kenan, K., Mack, K. A., \& Paulozzi, L. (2012). Trends in prescriptions for oxycodone and other commonly used opioids in the United States, 2000-2010. Open Medicine, 6(2), $41-47$.

Kerr, T., et al. (2007). Predictors of non-fatal overdose among a cohort of polysubstanceusing injection drug users. Drug and Alcohol Dependence, 87(1), 39-45.

Kinlock, T. W., et al. (2008). A study of methadone maintenance for male prisoners: 3month postrelease outcomes. Criminal Justice Behavior, 35, 34-47.

Kinlock, T. W., et al. (2009). A randomized clinical trial of methadone maintenance for prisoners: Results at 12 months postrelease. Journal of Substance Abuse Treatment, 37(3), 277-285.

Kopak, A. M., Lawson, S. W., \& Hoffmann, N. G. (2018). Criminal justice contact and relapse among patients seeking treatment for opioid use disorder. Journal of Drug Issues, 48(1), 134-147.

Lee, J. D., et al. (2015). Opioid treatment at release from jail using extended-release naltrexone: A pilot proof-of-concept randomized effectiveness trial. Addiction, 110(6), 1008-1014.

Leger, D. L. (2014). Police carry special drug to reverse heroin overdose. USA Today.

MacArthur, G. J., et al. (2012). Opiate substitution treatment and HIV transmission in people who inject drugs: Systematic review and meta-analysis.

Mattick, R. P., et al. (2009). Methadone maintenance therapy versus no opioid replacement therapy for opioid dependence. Cochrane Database of Systematic Reviews, 3, CD002209.

Matusow, H., et al. (2013). Medication assisted treatment in US drug courts: Results from a nationwide survey of availability, barriers and attitudes. Journal of Substance Abuse Treatment, 44(5), 473-480.

Merrall, E. L., et al. (2010). Meta-analysis of drug-related deaths soon after release from prison. Addiction, 105(9), 1545-1554.

Miller, H. V., Miller, J. M., \& Barnes, J. C. (2016). Reentry programming for opioid and opiate involved female offenders: Findings from a mixed methods evaluation. Journal of Criminal Justice, 46, 129-136.

Miller, J. M., Griffin, O. H., \& Gardner, C. M. (2016). Opiate treatment in the criminal justice system: A review of crimesolutions.gov evidence rated programs. American Journal of Criminal Justice, 41(1), 70-82.

Munetz, M. R., \& Griffin, P. A. (2006). Use of the sequential intercept model as an approach to decriminalization of people with serious mental illness. Psychiatric Services, 57(4), 544-549.

NaloxBox (2018). What is a NaloxBox. 
National Association of Drug Court Profressionals 2010. Resolution of the Board of Directions: On the availability of medically assisted treatment (M.A.T.) for addiction in drug courts.

Nunn, A., et al. (2009). Methadone and buprenorphine prescribing and referral practices in US prison systems: Results from a nationwide survey. Drug and Alcohol Dependence, 105(1), 83-88.

Paris, J. E. (2009). Jail intake screening. American college of correctional physicians.

Parmar, M. K. B., et al. (2017). Randomized controlled pilot trial of naloxone-on-release to prevent post-prison Opiod overdose deaths. Addiction, 112, 502-515.

Pennsylvania Board of Probation and Parole (2015). Parole offices now supplied with lifesaving Naloxone to combat heroin and opioid overdoses.

Prendergast, M. (2009). Interventions to promote successful re-entry among drug-abusing parolees. Addiction Science and Clinical Practice, 5, 4-13.

Rando, J., Broering, D., Olson, J. E., et al. (2015). Intranasal naloxone administration by police first responders is associated with decreased opioid overdose deaths. American Journal of Emergency Medicine, 33, 1201-1204.

Ray, B., \& K, O. D. D. A. K. (2015). Police officer attitudes towards intranasal naloxone training. Drug and Alcohol Dependence, 146, 107-110.

Rich, J. D., et al. (2015). bMethadone continuation versus forced withdrawal on incarceration in a combined US prison and jail: a randomised, open-label trial. The Lancet, 386(9991), 350-359.

Rudd, R., et al. (2016). Increases in drug and opiod overdose deaths-United States, 20002014. Morbidity and Mortality Weekly Reports, 64(50-51), 1378-1382.

Seal, D. W., et al. (2007). A longitudinal, qualitative analysis of the context of substance use and sexual behavior among 18- to 29-year-old men following their release from prison. Social Science and Medicine, 11, 2394-2406.

Sharma, A., et al. (2016). Pharmacotherapy for opioid dependence in jails and prisons: Research review update and future directions. Substance Abuse and Rehabilitation,
$7,27$.

State of New York 2015-2016 (2015). Regular session bill 4239-B N.Y. senate.

Strang, J., Bird, S. M., \& Parmar, M. K. B. (2013). Take-home emergency naloxone to prevent heroin overdose deaths after prison release: Rationale and practicalities for the N-ALIVE randomized trial. Journal of Urban Health, 90(5), 983-996.

Substance Abuse and Mental Health Services Administration 10 treatment for offenders under community supervision, In Substance abuse treatment for adults in the criminal justice system. 2005, Center for Substance Abuse Treatment: Rockville, MD.

U.S.D.O. Justice (2016). Adult drug court discretionary grant program FY 2016 competitive grant accouncement. Bureau of Justice Assistance.

US law enforcement who carry Naloxone (2017). North Carolina harm reduction coalition Vestal, C. (2016). At Rikers Island, a legacy of medication-assisted opioid treatment. Stateline: The pew charitable trusts.

Wagner, K. D., Bovet, L., Haynes, B., et al. (2016). Training law enforcement to respond to an opioid overdose with naloxone: Impact on knowledge, attitudes and interactions with community members. Drug and Alcohol Dependence, 165, 22-28.

Wickersham, J. A., Azar, M. M., Cannon, C. M., Altice, F. L., \& Springer, S. A. (2015) Validation of a Brief Measure of Opioid Dependence: The Rapid Opioid Dependence Screen (RODS). Journal of correctional health care: the official journal of the National Commission on Correctional Health Care, 21(1), 12-26. http://dx.doi.org/10.1177/ 1078345814557513

Wolitski, R. J., \& t.P.S.S. Group (2006). Relative efficacy of a multisession sexual riskreduction intervention for young men released from prison in 4 states. American Journal of Public Health, 96, 1854-1861.

World Health Organization Dept. of Mental Health Substance Abuse, W.H.O. and U.N.O.o.D.a.C (2009). International narcotics control board. Guidelines for the psychosocially assisted pharmacological treatment of opioid dependence. World Health Organization. 